\title{
Perspective
}

\section{Museums beyond neutrality}

\author{
Henry J Evans, Line B Nicolaisen, Sara TougaArd \& Marianne Achiam \\ Research group on Science Education in Out-of-school Settings \\ Department of Science Education, University of Copenhagen
}

More and more, museums are facing demands of accountability. The days are over when museums could legitimise their place in society simply by referring to the traditional functions of collecting, researching and disseminating (Black 2012, Achiam \& Sølberg 2017). Today, urges for museums to clarify their contributions to broader society come from many different sources: governments, who may allocate funding based on an institution's potential to generate financial returns (Rex 2019) or public health benefits (Desmarais et al. 2018); historians and indigenous experts, who critique the colonialist structures that enable museums to retain property rights to objects looted from former colonies (Knott 2018, Bakare 2019, Owen 2020); or scholars of cultural history, who demand that the white, western, male gaze prevalent in many exhibitions be replaced with a more diverse range of perspectives (Levin 2010, Robinson 2017, Balle 2019).

We suggest that these and other demands for accountability may be symptomatic of a general frustration with museums feigned neutrality (Janes \& Grattan 2019), and therefore an expression of an underlying societal need for museums to declare themselves more openly and explicitly. By neutrality, we mean not being engaged, or decided, on either side of an issue. As we shall argue in this position paper, a neutral position is neither possible nor, indeed, desirable for museums. We develop our argument by drawing on examples from research as well as from recent conversations in the museum community, and conclude by considering the implications of our proposal for museum practice. We focus on science museums (natural history museums, science and technology museums and science centres) because this is our collective area of expertise, and because realisations of the non-neutrality of the scientific endeavour have been much longer in the making in the natural sciences than in other disciplines. Even so, the arguments we make could be considered in other contexts and across museum genres.

\section{MUSEUMS ARE NOT NEUTRAL}

First of all, we contend that the institution of the museum is not, nor has it ever been, neutral. Evidence of the value-ladenness of museums comes from many quarters. Kathleen McLean says about museum practice:

Even in the earliest temples of the muses, someone set forth some object for others to experience, and 


\section{Henry J Evans, Line B Nicolaisen, Sara Tougaard \& Marianne Achiam}

who selected what for whom is the question at the heart of all conversation about exhibitions. The objects may be trophies of conquest, curious things from the natural world, masterpieces, or constructed environments, but embedded in their presentation is material evidence of the presenter's intentions and values (McLean 1999, 83).

What McLean is referring to here is that the simple act of setting forth objects in exhibitions is not neutral; it is rather an expression of institutional authority intended to prompt certain reflections among audiences. This is so, even though the intentions of exhibition designers are often hidden from public view, or even unconscious (McLean 1999).

The manifestations of museums that emerged in Europe in the sixteenth century, the curiosity cabinets or Wunderkammern, explicitly drew on 'exploration' and colonisation of other parts of the world. Today, the collections of many natural history museums in the Global North remain based on objects and specimens collected from former colonies, when the rights of westerners to take them was often not questioned (Norris 2017, Steinhauer 2018). Often, the dissemination of these objects and specimens largely ignores or downplays their provenance (Balle 2019).

Other types of museums have similarly nonneutral roots. For instance, the emergence of science centres in North America in the late 1960s was a response to the perceived success of science in the Second World War, but also a reaction to the successful launch of the satellite Sputnik by the Soviet Union and the resulting worry about the technological gap between the Soviet Union and the western nations. The appearance of science centres thus manifested an urge to create a scientifically competitive public (Ogawa et al. 2009) - hardly a neutral or non-ideological position.
Today, reduced public funding for museums prompts them to seek financial support from other avenues. This poses further questions about neutrality, as exemplified by the recent refurbishment of the fossil hall of the Smithsonian's National Museum of Natural History. Rieppel (2019) reported how this refurbishment was made possible by a donation from David Koch, an American multi-millionaire. With his brother Charles, David Koch was a key funder for climate change denialism, and the refurbished fossil hall that he helped fund has been accused of whitewashing the present climate crisis by making it seem part of a natural continuum, rather than a problem caused by human activity (Little 2015). The choice of downplaying or ignoring evidence of anthropogenic climate disruption in an exhibition that addresses climate is a curatorial decision, certainly, but not a neutral one.

To be sure, we are not seeking here to condemn the use of private funding in the development and maintenance of museum practices, although it has been argued that museums should completely avoid funding from certain sponsors (cf. Lyons \& Economopoulos 2015). We acknowledge that donations and funding from private organisations are a fact of life for many, if not all, museums. Nor are we advocating that those institutions whose genealogy is intertwined with values and ideology should suddenly cease to exist! Our critique here is of positions that tend to obscure the ideological foundations of museums and their practices.

\section{NeUtrality IS NOT POSSIBLE}

Although the examples we have given in the preceding can be seen as proof of existence of non-neutrality in museums and their 
practices, we would like to take our argument one step further. We claim that a neutral 'view from nowhere' (Haraway 1988) is impossible, because such a viewpoint simply does not exist. Even though objectivity has historically been an important part of the self-image of science (Reiss \& Sprenger 2017), science is not culture-free, and cannot produce culturefree, ahistorical knowledge (Brickhouse 2001). This means that attempts to maintain a disinterested and objective position on science by disseminating just 'the facts' flies in the face of research that shows how science is, among other things, gendered, raced and classed (for example Harding 1986, Code 1991, Leslie et al. 2015, Wong 2016). In the words of Jillian Steinhauer, "claiming not to take a position is actually a way of taking one - it means supporting the status quo" (Steinhauer 2018).

Even so, the enlightenment view of science that positions it as objective, disembodied and universally true has long characterised public engagement efforts (Davies 2014). This is a problem, because the enlightenment perspective appeals to only a fraction of the public: typically middle-class, well-educated people. This results in feelings of being excluded among many members of the public who are left out, for instance those from lower socioeconomic groups, from minority ethnic groups or older adults (Garibay 2011, Dawson 2014, OECD 2018). We thus contend that not only is neutrality impossible, but also that feigning neutrality (by supporting the status quo) can seem excluding to a wide diversity of publics.

\section{(Feigning) NEUTRALITY IS NOT DESIRABLE}

Finally, we suggest that rather than trying to conceal the ideological, political, institutional and cultural conditions that shape their practices, museums should openly disclose those for selecting, displaying and engaging with certain aspects of science. We argue that rather than risking their reputation as trusted communicators (cf. Janes 2013, Rodegher \& Freeman 2019) or alienating their funders (cf. Janes \& Sandell 2019), this disclosure can maintain and strengthen museums' credibility. This is because even though feigning neutrality may seem to justify a museum's focus on telling the facts and effectively absolve it from having to consider the implications of science for society, actually the feigned neutrality position just places this responsibility squarely on the visitors' shoulders (Rodegher \& Freeman 2019). This displacement of responsibility seriously undermines the educational mission of museums (Janes \& Grattan 2019) in a climate where they are increasingly being called upon to justify themselves. In other words: if museums, the stewards and repositories of scientific thinking (Janes \& Sandell 2019) cannot engage the public in reflecting on how science and society mutually affect each other, who can?

On a positive note, the growing movement among museums to create equitable and inclusive experiences, decolonise their collections, and address social justice seem to be evidence of a commitment to jettison notions of neutrality, and embrace a more transparent point of view. We encounter international examples of this movement, including the newly established museums of climate change in Hong Kong, New York and Oslo. We also encounter more local examples of this commitment, as exemplified by this comment from a museum professional close to us:

The activist tendency among museums is, as I see it, on the rise. Museums give their points of view on current debates, and use their position to suggest solutions to on-going 
societal issues. We witnessed this, for instance, in connection with the election of Trump, when several American museums exhibited works originating from the seven countries Trump banned immigration from.

At our museum, we talk about how this is a tendency that cannot be overlooked in our present society and the time we live in. Moreover, that it helps create trustworthiness in museums when they take a stance based on a scientific rather than a political point of view (Anonymous, personal communication, 20/10/19).

We believe the brief examples provided here represent different ways for museum professionals to respond to a broader societal need for museums to make their purposes and intentions explicit. In the final sections of this text, we offer principled suggestions about what these responses might look like from our perspective.

\section{WHAT MIGHT NON-NEUTRALITY LOOK LIKE IN MUSEUMS?}

As researchers in the natural sciences, we do not claim to have in-depth expertise in the detailed workings of science museums. In the following, we limit ourselves to briefly remarking on the general features of what non-neutrality could look like across the museum pillars of collections, research and dissemination. We are well aware that these suggestions are slightly removed from everyday museum practice, and require operationalisation. We hope the museum professionals who read this text will consider these suggestions in the constructive spirit in which we have attempted to write them.

Collections. Even though not all science museums have collections (e.g. science centres), for many institutions they play an important role in research and visitor engagement.
Although the historical asymmetry between those who collect and those who provide the specimens has gradually been replaced with much more equitable practices (Norris 2017), other problems related to the sustainability of collections have emerged. In particular, consumerist and materialist aspects of collecting have come to the forefront of discussions, given the increasing costs of maintaining and expanding collections (Bradley et al. 2014) coupled with sometimes vague claims of preserving heritage for posterity (Allmon 1994; Janes \& Sandell 2019). For museums, non-neutrality could consist of being explicit about how the accumulation of specimens and objects (and the related expenditure) can help us understand the problems we face as a global society, such as the biodiversity crisis (Suarez \& Tsutsui 2004) or climate change (Robbirt et al. 2011), or serve as repositories of technological memory as we search for solutions to modernday problems (Janes \& Sandell 2019).

Research. The scope of present-day museum research goes well beyond the descriptive classification that characterised early work. New analytical techniques, digitalisation and other developments has multiplied the contributions of museum research to society (Howarth 2017) where it provides crucial insights on public health (including pandemics), agriculture, habitat loss and many other problems (Suarez \& Tsutsui 2004). Current museum research thus distinguishes itself from the 'value-free' stance that has been a historical part of the self-image of the natural sciences (cf. Reiss \& Sprenger 2017). Declaring this non-neutrality could consist of explicating what sustainability values guide the museum's research, and how those values shape its identification of problems, formulation of research questions, and findings (cf. Schneider et al. 2019). Whether those findings are ultimately used to argue for 
changes in government policy or to promote informed civic engagement (Achiam \& Sølberg 2017, Howarth 2017), we claim that transparency about how they came about will strengthen the credibility of the museum.

Dissemination. Finally, a science museum's dissemination activities are its most immediate interface with the public, and thus where a nonneutral stance will have the greatest impact on public perception. Just like museums' collections and research activities have changed over time, so have its dissemination activities, perhaps most obviously in the case of exhibitions. Here, early communication models intended to show the scientific primacy of the object have been gradually replaced with models that acknowledge the role of the visitor's prior knowledge and experiences (cf. Achiam 2016). Today, the most progressive exhibitions are making important steps towards fully embracing and declaring the cultural diversity and significance of the displayed objects and their provenance (Blond 2017). Therefore, non-neutral exhibitions in museums are those that openly question authoritative or canonical accounts of science, and engage their communities in negotiating the meaning of scientific objects and practices (Sandholdt \& Achiam 2019). This engagement can take place in the design phase through co-curation or codevelopment processes with relevant publics (for example indigenous communities or people impacted by climate change, Anderson \& Hadlaw 2018) and by explicitly including and contextualising the multiple voices of those publics in the exhibition (Blond 2017).

\section{Conclusion}

In this paper, we have argued that museums have never been neutral, nor is it a desirable position. In fact, we believe that an explicitly non-neutral stance presents the museum community with an opportunity to clarify their many contributions to broader society, thereby increasing their relevance and inclusiveness to the public. We thus invite the community of (science) museum professionals to consider the day-to-day and long-term implications of a museum beyond neutrality.

\section{REFERENCES}

Achiam, Marianne 2016. "The role of the imagination in museum visits.” Nordisk Museologi 16:1, 89100. doi: $10.5617 / \mathrm{nm} .3066$.

Achiam, Marianne \& Jan Sølberg 2017. "Nine metafunctions for science museums and science centres." Museum Management and Curatorship 32:2, 123-143. doi:10.1080/09647775.2016. 1266282.

Allmon, Warren D 1994. "The Value of Natural History Collections." Curator: The Museum Journal 37:2, 83-89. doi: 10.1111/j.2151-6952.1994.tb01011.x. Anderson, Katherine \& Jan Hadlaw 2018. "The Canada Science and Technology Museum.” Technology and Culture 59:3, 781-786. doi: 10.1353/tech.2018.0066.

Bakare, Lanre 2019. "British Museum 'has head in sand' over return of artefacts." The Guardian, June 21. https://www.theguardian.com/culture/2019/ jun/21/british-museum-head-in-sand-returnartefacts-colonial (7 November 2020)

Balle, Maja 2019. "Naturarven fra kolonitiden." Danske Museer, May 9. Retrieved from https:// danskemuseer.dk/naturarven-fra-kolonitiden/ (7 November 2020)

Black, Graham 2012. Transforming Museums in the Twenty-first Century. London: Routledge.

Blond, Kara 2017. "Imagining the future of natural history museum exhibitions.” In Eric Dorfman (ed.). The Future of Natural History Museums. London: Routledge, 103-118.

Bradley, Robert D, Lisa C. Bradley, Heath J. Garner 


\section{Henry J Evans, Line B Nicolaisen, Sara Tougaard \& Marianne Achiam}

\& Robert J. Baker 2014. "Assessing the Value of Natural History Collections and Addressing Issues Regarding Long-Term Growth and Care." BioScience 64:12, 1150-1158.

Brickhouse, Nancy W 2001. "Embodying science: A feminist perspective on learning." Journal of Research in Science Teaching 37:5, 441-458.

Code, Lorraine 1991. What Can She Know? Feminist Theory and the Construction of Knowledge. Cornell University Press.

Davies, Sarah R 2014. "Knowing and loving: Public engagement beyond discourse." Science \& Technology Studies 28:3, 90-110.

Dawson, Emily 2014. "Not designed for us: How informal science learning environments socially exclude low-income, minority ethnic groups." Science Education 98:6, 981-1008. doi: 10.1002/ sce. 21133 .

Desmarais, Sarah, Laura Bedford \& Helen Chatterjee 2018. "Museums as spaces for wellbeing: A second report from the national alliance for museums, health and wellbeing." National Alliance for Museums, Health and Wellbeing. Retrieved from www.museumsandwellbeingalliance.wordpress. com (7 November 2020)

Garibay C 2011. "Responsive and accessible: How museums are using research to better engage diverse cultural communities." ASTC Dimensions, January-February 4.

Haraway, Donna 1988. "Situated knowledges: The science question in feminism and the privilege of partial perspective." Feminist Studies 14:3, 575-599. doi: 10.2307/3178066.

Harding, Sandra 1986. The Science Question in Feminism. Ithaca: Cornell University Press.

Howarth, Frank 2017. “The future of research in natural history museums." In Eric Dorfman (ed.). The Future of Natural History Museums. London: Routledge, 65-81.

Janes, Robert 2013. Museums and the Paradox of Change. London: Routledge.

Janes, Robert \& Naomi Grattan 2019. “Museums
Confront the Climate Challenge." Curator: The Museum Journal 62:2, 97-103. https://doi. org/10.1111/cura.12298

Janes, Robert \& Richard Sandell 2019. “Posterity has arrived. The necessary emergence of museum activism.” In Robert Janes and Richard Sandell (eds.). Museum Activism. London: Routledge, 1-22.

Knott, Jonathan 2018. "Historian calls for repatriation of objects to former colonies." Museums Association, May 30. Retrieved from https://www. museumsassociation.org/museums-journal/ news/30052018-olusoga-calls-for-objectrepatriation (7 November 2020)

Leslie, Sarah-Jane, Andrei Cimpian, Meredith Meyer \& Edward Freeland 2015. "Expectations of brilliance underlie gender distributions across academic disciplines.” Science 347:6219, 262-265.

Levin, Amy K 2010. "Straight talk: Evolution exhibits and the reproduction of heterosexuality." In Amy Levin (ed.). Gender, Sexuality and Museums. A Routledge Reader. London: Routledge, 201-212.

Little, Ryan 2015. "Fact-checking the Smithsonian's Koch-funded climate change exhibition." Hyperallergic, July 2.https://hyperallergic.com/219544/ fact-checking-the-smithsonians-koch-funded-climate-change-exhibition/ (7 November 2020)

Lyons, Steve \& Beka Economopoulos 2015. "Museums must take a stand and cut ties to fossil fuels." The Guardian, May 7.https://www.theguardian.com/ environment $/ 2015 / \mathrm{may} / 07 /$ museums-must-takea-stand-and-cut-ties-to-fossil-fuels (7 November 2020)

McLean, Kathleen 1999. "Museum exhibitions and the dynamics of dialogue." Daedalus 128:3, 83-107.

Norris, Christopher A 2017. "The future of natural history collections." In Eric Dorfman (ed.). The Future of Natural History Museums. London: Routledge, 13-28.

OECD 2018. "Education at a Glance 2018." OECD Indicators. Paris: OECD Publishing.

Ogawa, Rodney T, Molly Loomis \& Rhiannon Crain 2009. "Institutional history of an interactive 
science center: The founding and development of the Exploratorium." Science Education 93:2, 269-292. doi: 10.1002/sce.20299.

Owen, Brenna 2020. "Indigenous experts call for repatriation of cultural artifacts and remains from museums." The Globe and Mail, March 6. Retrieved from https://www.theglobeandmail. com/canada/article-indigenous-experts-callfor-repatriation-of-cultural-artificats-and/ (7 November 2020)

Reiss, Julian and Jan Sprenger 2017. "Scientific objectivity”. In Edward N Zalta (ed.). The Stanford Encyclopedia of Philosophy.

Rieppel, Lukas 2019. “The Smithsonian's new dinosaur hall is a marvel. But its ties to David Koch are a problem." The Washington Post, June 9. Retrieved from https://www.washingtonpost. com/outlook/2019/06/09/smithsonians-newdinosaur-hall-is-marvel-its-ties-david-koch-areproblem/\#comments-wrapper (7 November 2020)

Rex, Bethany 2019. "Which museums to fund? Examining local government decision-making in austerity." Local Government Studies 46:2, 186205. doi: 10.1080/03003930.2019.1619554.

Robbirt, Karen M, Anthony J. Davy, Michael J. Hutchings \& David L. Roberts 2011. "Validation of biological collections as a source of phenological data for use in climate change studies: a case study with the orchid Ophrys sphegodes." Journal of Ecology 99:1, 235-241. doi: 10.1111/j.1365-2745.2010.01727.x.

Robinson, Helena 2017. "Is cultural democracy possible in a museum? Critical reflections on Indigenous engagement in the development of the exhibition Encounters: Revealing Stories of Aboriginal and Torres Strait Islander Objects from the British Museum.” International Journal of Heritage Studies 23:9, 860-874. doi: 10.1080/13527258.2017.1300931.

Rodegher, Sandra L and Stacy Vicario Freeman 2019. "Advocacy and activism. A framework for sustainability science in museums." In Robert
Janes and Richard Sandell (eds.). Museum
Sandholdt, Catharina Thiel \& Marianne Achiam 2018.

"Engaging or transmitting? Health at the science centre." Nordisk Museologi 2-3, 136-151. doi: 10.5617/nm.6661.

Schneider, Flurina, Andreas Kläy, Anne B. Zimmermann, Tobias Buser, Micah Ingalls \& Peter Messerli 2019. "How can science support the 2030 Agenda for Sustainable Development? Four tasks to tackle the normative dimension of sustainability." Sustainability Science 14:6, 15931604. doi: 10.1007/s11625-019-00675-y.

Steinhauer, Jillian 2018. "Museums have a duty to be political." The Art Newspaper, March 20. Retrieved from https://www.theartnewspaper.com/ comment/museums-have-a-duty-to-be-political (7 November 2020)

Suarez, Andrew V \& Neil D. Tsutsui 2004. “The value of museum collections for research and society." BioScience 54:1, 66-74. doi: 10.1641/0006-3568 (2004)054[0066:tvomcf]2.0.co;2.

Wong, Billy 2016. Science Education, Career Aspirations and Minority Ethnic Students. Hampshire: Palgrave Macmillan.

Henry James Evans, PhD student

Department of Science Education,

Universitetsparken 5, 2100 København, Danmark hje@ind.ku.dk

https://www.ind.ku.dk/english/research/

science-education-in-out-of-school-settings/

Line Nicolaisen, PhD student

nicolaisen@ind.ku.dk

Sara Tougaard, Consultant

sara.tougaard@ind.ku.dk

Marianne Achiam, Associate Professor achiam@ind.ku.dk 